Research Article

\title{
Comparison of Paraquat Herbicide Removal from Aqueous Solutions using Nanoscale Zero-Valent Iron-Pumice/ Diatomite Composites
}

\author{
Abbas Khodabakhshi (D), ${ }^{1}$ Fazel Mohammadi-Moghadam $\left(\mathbb{D},{ }^{1}\right.$ Mohammad Mehdi Amin (D), ${ }^{2}$ \\ Sara Hamati $\left(\mathbb{D},,^{1,3}\right.$ and Shakila Hayarian $\mathbb{( D}^{1}$ \\ ${ }^{1}$ Department of Environmental Health Engineering, School of Health, Shahrekord University of Medical Sciences, \\ Shahrekord, Iran \\ ${ }^{2}$ Department of Environmental Health Engineering, School of Health, Isfahan, Iran \\ ${ }^{3}$ Student Research Committee, Shahrekord University of Medical Sciences, Shahrekord, Iran
}

Correspondence should be addressed to Shakila Hayarian; shakila.hayarian@gmail.com

Received 4 October 2021; Accepted 5 December 2021; Published 21 December 2021

Academic Editor: Antonio Brasiello

Copyright (C) 2021 Abbas Khodabakhshi et al. This is an open access article distributed under the Creative Commons Attribution License, which permits unrestricted use, distribution, and reproduction in any medium, provided the original work is properly cited.

\begin{abstract}
Paraquat is the most important herbicide of the bipyridyl group. The aim of the present study was to compare the removal of paraquat herbicide from aqueous solutions using nanoscale zero-valent iron-pumice/diatomite composites. In this study, nZVI was supported with diatomite and pumice. Scanning electron microscopy (SEM) analysis, X-ray diffraction spectroscopy (XRD), Fourier transform infrared spectrometry (FTIR), and specific surface area tests (BET) were used to evaluate the properties of nanoadsorbents. The residual concentration of paraquat in aqueous solution was detected by high-performance liquid chromatography (HPLC). Then, the effects of different variables including the pollutant concentration, contact time, temperature, adsorbents (D-nZVI and P-nZVI) dose, and pH, were investigated in a lab scale batch system. The results showed that the optimal $\mathrm{pH}$ for both processes was 3.74. In optimal conditions, the efficiencies of D-nZVI and P-nZVI were 92.76\% and $85.28 \%$, respectively. In addition, isotherm and adsorption kinetics studies indicated that P-nZVI follows the Langmuir and Freundlich isotherm models, and D-nZVI follows the Langmuir isotherm model, and both processes follow pseudo-second-order kinetics. The results indicated that the synthesized nanoparticles were suitable for removing paraquat from aqueous solutions. Both adsorbents were found to be very effective in removing similar compounds at ambient temperature in a short time.
\end{abstract}

\section{Introduction}

Currently, in many countries, it is observed that the use of pesticides for agriculture causes problems such as water, soil, and air pollution [1]. Among pesticides, herbicides are widely used in agriculture. Their excessive persistence can state serious risks to human health, aquatic life, and animals [2]. Paraquat is one of the most common herbicides, especially in developing countries. Paraquat is a nonselective herbicide that belongs to the category of bipyridines and is used as a moisture absorber in products such as potatoes, sugarcane, rice, coffee, beans, and to kill weeds [3]. The characteristics of paraquat are listed in Table S1.
The use of this compound may present potential environmental hazards such as respiratory poisoning, hypersensitivity, gastrointestinal obstruction, neurological problems, pulmonary fibrosis, and Parkinson's disease for humans and animals [4-6]. The severity of paraquat poisoning depends on many factors and conditions, such as the duration of exposure, the route, and the amount of poison [7]. To protect human health and the environment from the harmful effects of paraquat herbicide, advanced and practical treatment processes are necessary to remove it from the water [8]. Common purification processes for removing paraquat generally include reductive processes such as adsorption on porous 
solids, membrane filtration, a combination of adsorption and membrane filtration [9], and advanced oxidation processes (AOPs) $[10,11]$.

Adsorption is the simplest, most economical and most effective method for wastewater treatment among all of the processes [12]. However, more effective materials development is very important to eliminate the effects of paraquat from aqueous solutions. Nanotechnology is one of the fastest growing sectors of the global economy. Based on the theoretical and empirical evidence and studies, zero-valent iron nanoparticles (nZVI) are widely used to remove pesticides, heavy metals, antibiotics, paints, and other contaminants from water due to their specific surface area, environmental safety, catalytic reduction capability, low cost, and easy to use $[13,14]$.

Zero-valent iron nanoparticles, due to their magnetic interaction and high surface energy, they tend to accumulate in their particles alone, which reduces the specific surface area of nZVI secondary iron contamination, separation and recovery problems after use, and its removal effects are restricted $[15,16]$. To prevent the accumulation of nZVI, a variety of materials are produced and used as carriers such as clay, grapheme, carbon, bentonite, and silica $[17,18]$. In addition, the porous structure of these compounds leads to high hydraulic conductivity which increases the rate of degradation in aqueous systems $[17,19,20]$.

Diatomite is a white, soft, light stone that has a unique natural crystalline structure and is composed of a fossilized diatom skeleton [21]. The highly porous structure of diatomite, low density, high permeability, small particle size, high adsorption capacity, high specific surface area, and its thermal and mechanical stability and hydraulic conductivity have led to its use as a filter, catalyst carrier, and effluent treatment [22]. Diatomite may be used as a carrier for nZVI due to its macroporous structure and excellent thermal and mechanical resistance [23].

Pumice is a porous volcanic rock that has a skeletal structure and a large surface. Pumice has open channels that allow water and ions to travel inside and outside the crystal structure. In addition, pumice can be easily processed. Pumice has been used in water treatment as an inexpensive adsorbent and filter. Pumice can stabilize more nZVI, so it is a better alternative than other supporters [24].

In this context, the present work aimed to prepare, characterize, and apply nZVI-pumice and nZVI-diatomite composites for removing paraquat from aqueous solutions. Furthermore, adsorption kinetics and adsorption isotherms were investigated. To the best of our knowledge, this is the first study that used nZVI-pumice and nZVI-diatomite composites for paraquat adsorption.

\section{Materials and Methods}

2.1. Materials and Supplies. In this study, iron (II) chloride tetrahydrate $(\geq 99 \%)$, sodium borohydride $(99 \%)$, acetonitrile (98\%), and ethanol (99.8\%) were purchased from Merck Company (Germany). Paraquat ( $\geq 99 \%)$, diatomite (99\%), and pumice (99\%) were purchased from Sigma-Aldrich Company (USA).
2.2. Preparation of $n Z V I$ and Diatomite (D-nZVI). $5 \mathrm{~g}$ of iron (II) chloride tetrahydrate $\left(\mathrm{FeCl}_{2} \cdot 4 \mathrm{H}_{2} \mathrm{O}\right)$ was added to a mixture of ethanol and deionized water $(75 \mathrm{~mL}$ of ethanol plus $25 \mathrm{~mL}$ of water). Then, $5 \mathrm{~g}$ of diatomite was added to this solution. Then, sodium borohydride $\left(\mathrm{NaBH}_{4}\right)$ was added dropwise under a hood with continuous stirring. After adding all of the borohydride solution, the mixture was left stirring for an additional $10 \mathrm{~min}$. The reduction of iron ions by borohydride ions can be represented according to equation (1).

$$
\mathrm{Fe}_{2}^{+}+2 \mathrm{BH}_{4}^{-}+6 \mathrm{H}_{2} \mathrm{O} \longrightarrow \mathrm{Fe}^{0}+2 \mathrm{~B}(\mathrm{OH})_{3}+7 \mathrm{H}_{2} \uparrow
$$

After the color change of the solution, the solids were separated from the solution by vacuum filtration, washed with ethanol, and dried in an oven at $50^{\circ} \mathrm{C}$ [25].

2.3. Preparation of $n Z V I$ and Pumice (P-nZVI). $1.5 \mathrm{~g}$ of pumice was used as a support material. Then, $5 \mathrm{~g}$ of $\mathrm{FeCl}_{2} \cdot 4 \mathrm{H}_{2} \mathrm{O}$ was added to a mixture of ethanol and water ( $75 \mathrm{~mL}$ of ethanol plus $25 \mathrm{~mL}$ of water). Thereafter, $\mathrm{NaBH}_{4}$ was added dropwise to the solution under a hood with constant stirring. After the color change of the solution, the solids were separated from the solution by vacuum filtration, washed with ethanol, and dried in an oven at $50^{\circ} \mathrm{C}$ [26].

2.4. Nanoparticle Characterization. An X-ray diffraction (XRD, PMD Philips X'Pert) analysis was used to identify the crystal structure of the synthesized nanosorbents. The existing functional groups on the prepared nanostructures were evaluated by Fourier transform analysis (FTIR, Bruker, Germany). Adsorbent surface morphology with a field emission scanning electron microscope (FESEM, ZEISS, model Sigma, Germany), elemental analysis of adsorbents by BET analysis (JW-BK132F) was used to measure the surface area of the produced materials.

2.5. Batch Studies. Batch experiments were performed in the Erlenmeyer with $250 \mathrm{~mL}$ of aqueous solution. The effects of $\mathrm{pH}(2-8)$, adsorbent dose $\left(0.5-2 \mathrm{~g} \cdot \mathrm{L}^{-1}\right)$, reaction time (10-100 $\mathrm{min})$, paraquat concentration $\left(0.5-4 \mathrm{mg} \cdot \mathrm{L}^{-1}\right)$, and temperature $\left(15-45^{\circ} \mathrm{C}\right)$ on paraquat removal using $\mathrm{D}$-nZVI and P-n-ZVI were investigated. The solutions were shaken in a temperature-controlled shaker (OS-300). Sampling was made at a certain time interval (10-100 min) and then, the samples were filtered with a syringe filter $(0.02 \mu \mathrm{m}$ pore size, Whatman Anotop 10), and stored at $4^{\circ} \mathrm{C}$ when needed, and analyzed within $48 \mathrm{~h}$ of collection [26]. All experiments were performed in triplicates.

2.6. Analytical Methods. Paraquat concentration in the sample was measured by reverse phase high-performance liquid chromatography (HPLC Agilent 1200) using a C-18 column (ODS HYPERSIL, $5 \mu \mathrm{m}, 4.6 \times 250 \mathrm{~mm}$, Agilent Technologies) with a mobile phase of water and acetonitrile (ACN: water 75:25 for paraquat analysis; HPLC method details: injection volume, $V=10 \mu \mathrm{L}$; paraquat 
$\mathrm{RT}=1.63 \mathrm{~min})$. Standard calibration methods were followed. In equation (2), $C_{0}$ and $C_{t}$ are the initial and final concentrations of the contaminant in $\mathrm{mg} \mathrm{L}^{-1}$; before and after batch experiments, respectively $[27,28]$.

$$
\text { removal efficiency } \%=\left[\frac{\left(C_{0}-C_{t}\right)}{C_{0}}\right] \times 100 \text {. }
$$

2.7. Experimental Design. One of the response surface methodology (RSM) approaches, that is widely usedp pin research, is the central composite design (CCD) [29]. In this study, RSM based on the CCD was used to evaluate the interaction effect on the response function (paraquat removal efficiency) and predict the best response rate. In order to design experiments with a CCD, minimal and maximum levels were given to design expert software, and the other levels were determined between the maximum and minimum points by the software. Including three repetitions, 150 experiments were performed for each method (D-nZVI and P-n-ZVI). A total of 300 experiments were performed.

\section{Results and Discussion}

3.1. Nanoparticle Characterization. According to Figure 1(a) in the D-nZVI sample, there are particles with a spherical morphology throughout the material, the size of which is about 80 to 100 nanometers. It is also known that the structure of this material is relatively dense and has fewer pores than the P-nZVI sample. Figure 1(b) shows that the morphology of the particles is pseudospherical, but this time the particle size is slightly smaller (between 60 and $80 \mathrm{~nm}$ ), and the particles are chained together to form strands in microscopic images.

To investigate the particle size distribution of these two samples, Image J software was used, and the sizes of 100 different particles in microscopic images were measured at the highest magnification, and the histogram related to this measurement is shown in Figure 2. As seen, about $40 \%$ of the visible particles in the D-nZVI sample have a size in the range of 80 to $100 \mathrm{~nm}$ and about $65 \%$ of the visible particles in the P-nZVI sample have a size in the range of 60 to $90 \mathrm{~nm}$, which indicates a smaller particle size than the first sample. The statistical parameters obtained from this particle size distribution are reported in Table S2.

$$
\mathrm{SD}=\frac{\left(\sum_{i=1}^{100}\left(X_{i}-\ddot{x}\right)\right)}{99} \text {. }
$$

The values of the standard deviation in Table S2 were obtained from equation (3). In equation (3), $X_{i}$ is the size of each particle, and $\ddot{x}$ is the average value for all of the particle sizes.

According to Table S2, the average particle size in the P-nZVI sample was about $78 \mathrm{~nm}$ which was much smaller than the D-nZVI sample which had an average particle size of about $92 \mathrm{~nm}$. Also, the amount of the smallest and largest particles for the P-nZVI sample compared to the D-nZVI sample indicates that the $\mathrm{p}-\mathrm{nZVI}$ composite is finer than the other sample. Figure 3 also shows the amount of porosity in the structure of these two materials.

According to Figure 3, the percentage of porosity in the D-nZVI sample was $11.69 \%$, while this percentage was $14.37 \%$ in the P-nZVI sample, which indicates a higher density of the D-nZVI than the P-nZVI sample. FT-IR and $\mathrm{XRD}$ tests were used to investigate the chemical nature and crystal structure of these two composites. The results of the FT-IR test are shown in Figure 4.

Figure 4(a) shows the peaks visible at $473 \mathrm{~cm}^{-1}$, $793 \mathrm{~cm}^{-1}$, and $1088 \mathrm{~cm}^{-1}$ in similar articles as characteristic carbonate ion $\left(\mathrm{CaCO}_{3}^{2-}\right)$ peaks in the molecular structure of calcium carbonate $[30,31]$. The peaks observed at $1088 \mathrm{~cm}^{-1}$ and $793 \mathrm{~cm}^{-1}$ are related to the symmetrical tensile vibration of carbonate ion bonds and the inplane flexural vibration of $\mathrm{CaCO}_{3}^{2-}$ ions $[30,32]$, and the tensile vibration of $\mathrm{Ca}-\mathrm{O}$ bonds in the wave $-473 \mathrm{~cm}^{3}$ showed absorption peaks [31]. In addition, the absorption peak visible at $1384 \mathrm{~cm}^{-1}$ is related to the flexural vibration of $\mathrm{C}-\mathrm{H}$ bonds, and the absorption peaks visible at the wave numbers of $2852 \mathrm{~cm}^{-1}$ and $2923 \mathrm{~cm}^{-1}$, respectively, are symmetric and asymmetric tensile vibrations of the same bonds in the structure of organic compounds [33]. Also, the flexural vibration and tensile vibration of the adsorbed water-related bonds in this composite have shown the absorption peak in the wave numbers of $1630 \mathrm{~cm}^{-1}$ and $3425 \mathrm{~cm}^{-1}$, respectively [34]. Therefore, based on the results, it is clear that the predominant chemical structure in this sample is calcium carbonate, and there are some organic compounds in this sample.

In the spectrum of the P-nZVI sample (Figure 4(b)), the peaks related to the symmetric and asymmetric tensile vibrations of the O-Si-O bonds are shown in the wave numbers of $873 \mathrm{~cm}^{-1}$ and $1020 \mathrm{~cm}^{-1}$, respectively $[35,36]$. In addition, the absorption peak appearing at $1450 \mathrm{~cm}^{-1}$ is related to the flexural vibration of $\mathrm{N}-\mathrm{H}$ bonds, and the absorption peaks visible in the wave numbers of $2853 \mathrm{~cm}^{-1}$ and $2923 \mathrm{~cm}^{-1}$, respectively, are the symmetric and asymmetric tensile vibrations of $\mathrm{C}-\mathrm{H}$ bonds in the structure of existing organic compounds [33]. Also, the flexural vibration and the tensile vibration of the bonds related to the adsorbed water in this composite have shown the absorption peak in the wave numbers of $1629 \mathrm{~cm}^{-1}$ and $3423 \mathrm{~cm}^{-1}$, respectively [34]. Therefore, it is clear that the predominant chemical structure in this sample is silicon oxide, and some organic compounds are also present in this sample. It should be noted that due to the fact that only chemical bonds can be detected in FT-IR spectra and zero-valent iron has no bond with other elements in the composite, the absence of this element in the FT-IR test results can be justified.

An XRD test was used to evaluate the crystal structure of the samples. In this test, by irradiating X-ray onto the crystal structure of a monocrystalline or polycrystalline material, while entering the X-ray into the crystalline structure of this material, after colliding with different crystal plates and reflecting at a certain angle of reflection, the courier shows. By putting these peaks together and drawing the X-ray diffraction pattern, we can understand the crystalline phases in the material under study [37]. X-ray diffraction patterns 

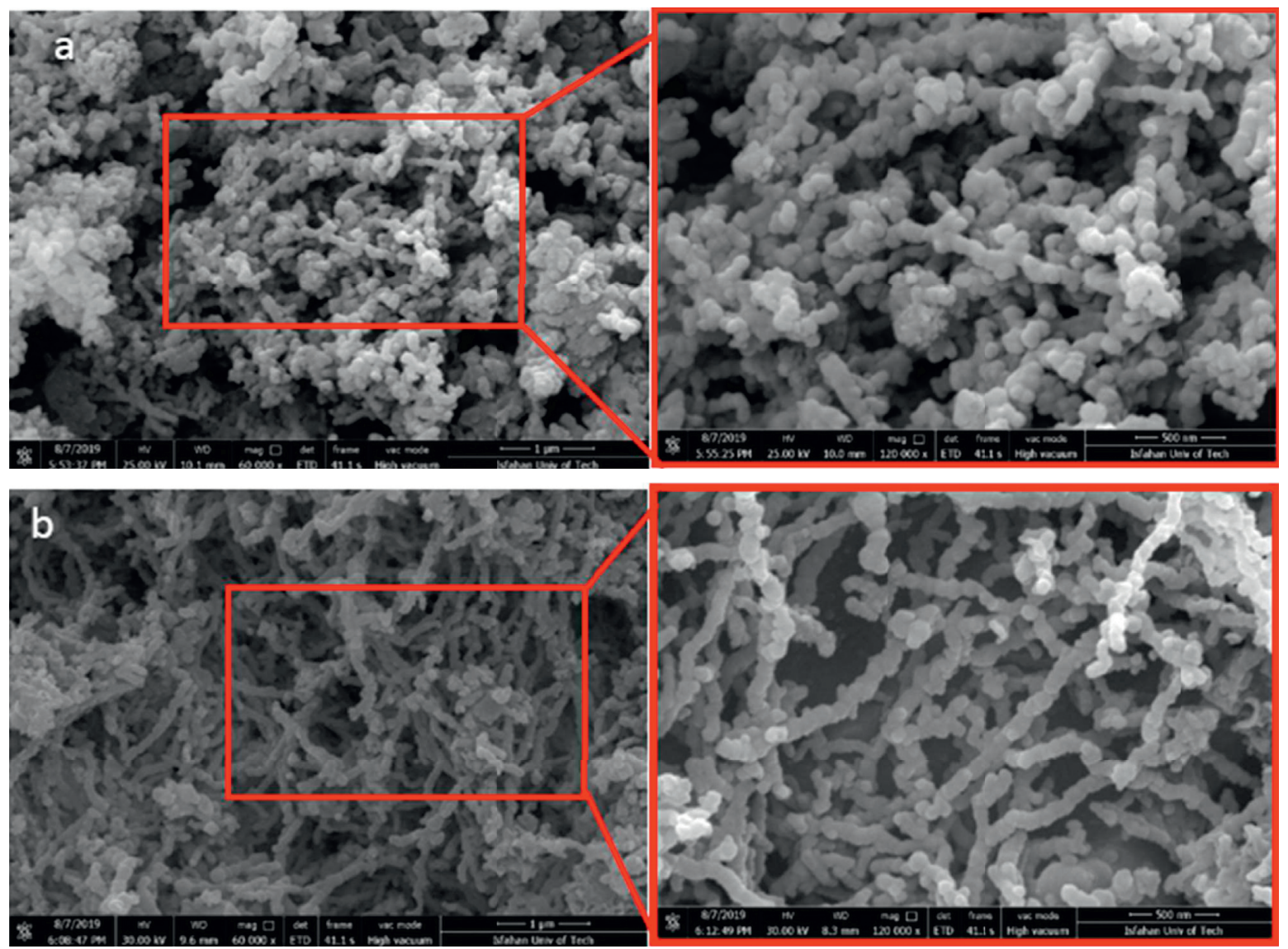

Figure 1: Fe-SEM images for (a) D-nZVI and (b) P-nZVI (mag 60,000 $\times 120,000 \mathrm{x}$ ).

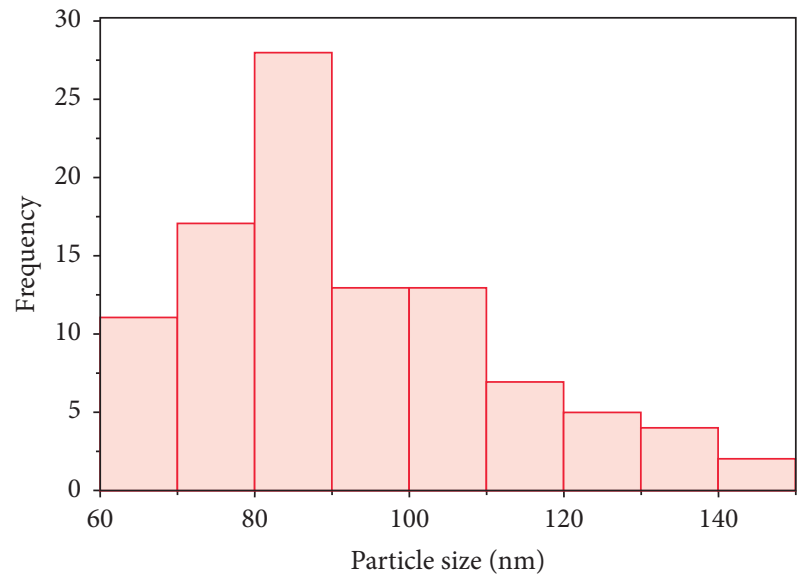

D-nZVI

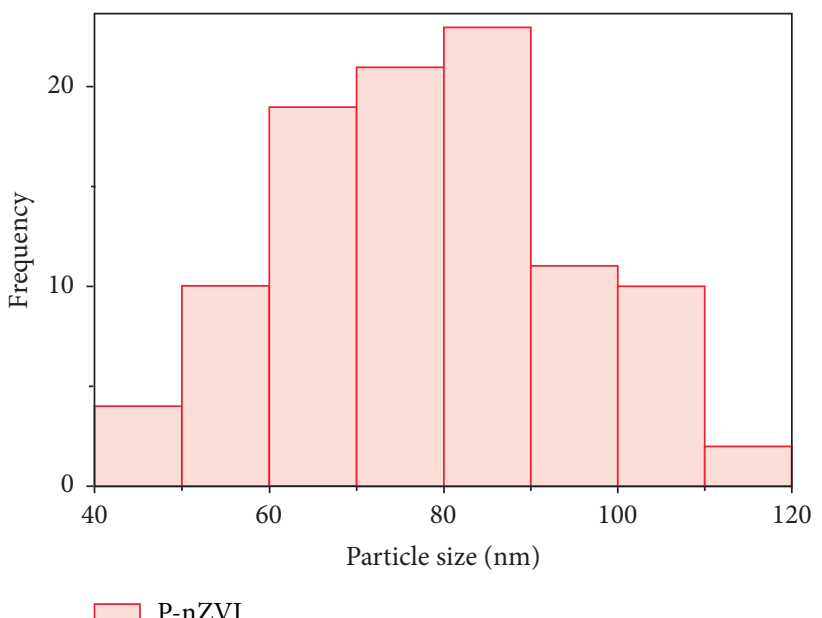

(b)

(a)

Figure 2: Particle size distribution histogram. (a) D-nZVI and (b) P-nZVI.

are shown in Figure 5. According to the diffraction pattern shown in Figure 5(a) and by adapting this diffraction pattern to the reference patterns by X'Pert software, two calcium carbonate materials (with rhombohedral crystal structure and reference code: JCPDS No: 01-085-0849) and zerovalent iron (with cubic crystal structure and reference code:
JCPDS No: 00-001-1267) have been identified. The presence of calcium carbonate in this sample confirms the results of the FT-IR test. The diffraction plate corresponding to each peak is marked on the same peak. In order to obtain the crystal size of each of these phases, equation (4), which is called the Debbie-Scherer relationship, has been used. 

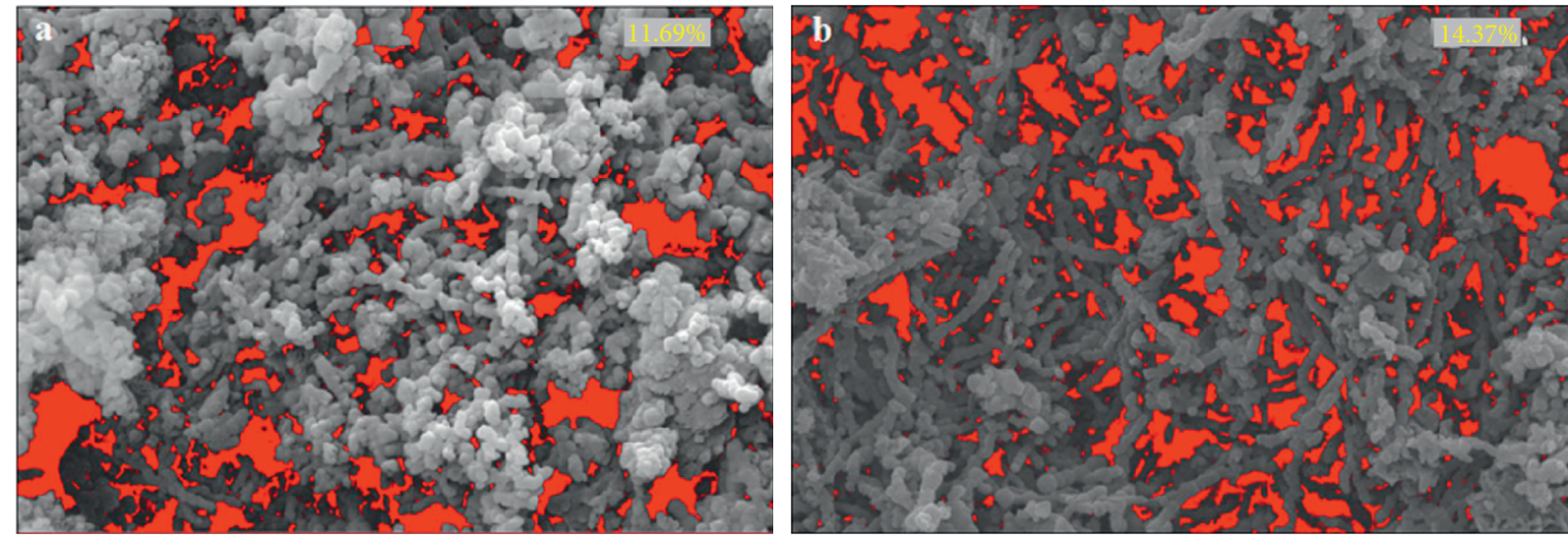

Figure 3: Percentage porosity of (a) D-nZVI and (b) P-nZVI composites using the ImageJ processing software.

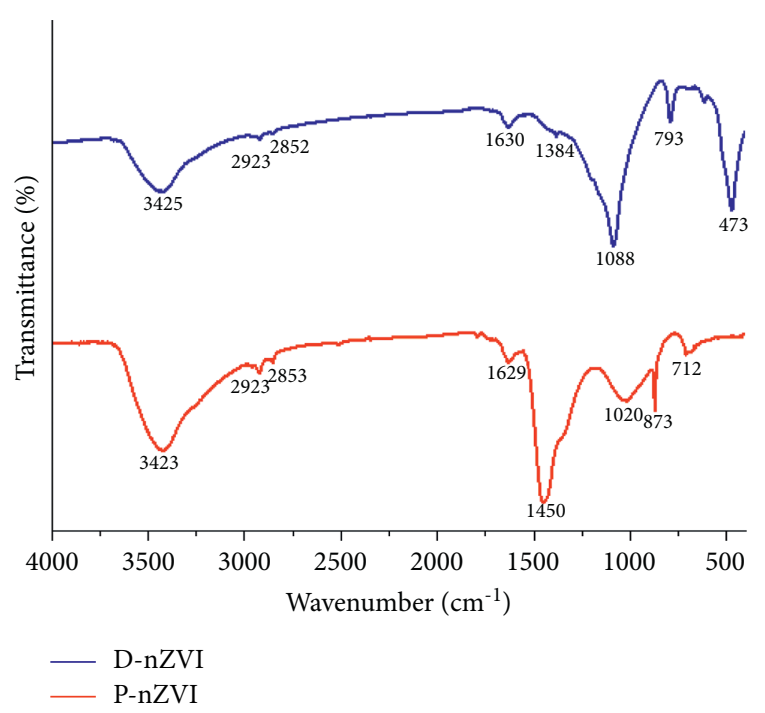

Figure 4: FTIR patterns of D-nZVI and P-nZVI.

$$
D=\frac{K \lambda}{B} \cos (\theta)
$$

In this equation, $\lambda$ is the $\mathrm{X}$-ray wavelength used (here $1.54 \AA$ ), $K$ is the shape factor (approximately equal to 0.9 ), $B$ is the peak width at half the height, and $\theta$ is the peak location. According to the equation, the crystal sizes for the calcium carbonate and zero-valent iron phases are 37.3 and $6.3 \mathrm{~nm}$, respectively. According to the diffraction pattern shown in Figure 5(b) and by adapting this diffraction pattern to the reference patterns, two silicon oxide materials (with tetragonal crystal structure and reference code: JCPDS No: 01076-0935) and zero-valent iron (with cubic crystal structure and reference code: JCPDS No: 00-001-1267) have been identified. The presence of silicon oxide in this sample confirms the results of the FT-IR test. In the diffraction pattern, the diffraction plate of each peak is specified on the same peak. Also, the values of crystal size obtained by the equation (4) for the phase of silicon oxide and zero-valent iron are 20.7 and $6.5 \mathrm{~nm}$, respectively.

The specific surface area was measured following the Brunauer-Emmett-Teller (BET) $\mathrm{N}_{2}$ method. The BET for
D-nZVI and P-nZVI were 59.682 and $40.189 \mathrm{~m}^{2} \mathrm{~g}^{-1}$, respectively.

3.2. $p H$ Effect. The results of the effect of $\mathrm{pH}$ on the removal efficiency of paraquat on adsorbents in Figure 6 indicate that the maximum removal rate was obtained at an acidic $\mathrm{pH}$ of 3.74. The highest removal rates for D-nZVI and P-nZVI were $95.14 \%$ and $92.07 \%$, respectively. The optimum $\mathrm{pH}$ in both processes is 3.74 . The $\mathrm{pH}$ solution is one of the important factors in controlling the degradation effect on chlorinated pollutants (equation (5)) [38].

$$
\mathrm{Fe}^{0}(\mathrm{~s})+\mathrm{H}^{+}+\mathrm{R}-\mathrm{Cl} \longrightarrow \mathrm{R}-\mathrm{H}+\mathrm{Fe}^{2+}+\mathrm{Cl}^{-1}
$$

The reaction between iron and chlorinated organic compounds occurs according to the equation [39]. As the $\mathrm{pH}$ of the solution decreased, the shell of nZVI particles (oxide and hydroxide coatings) separated under acidic conditions, and paraquat access to $\mathrm{Fe}^{0}$ was increased. Under higher $\mathrm{pH}$ values, the activity of iron oxide and hydroxide coating on the surface undoubtedly prevents access to the $\mathrm{Fe}^{0}$ level. However, with a further decrease in the $\mathrm{pH}$ of the solution, the removal efficiency decreases rapidly, which may be due to greater $\mathrm{Fe}^{0}$ ionization under strong acid conditions [39]. Also, at acidic pH, the soluble part of the iron ion and the hydroxyl radical oxidation power are higher. In a study carried out by Liu et al. to remove heavy metals by pumice with zero-valent iron nanoparticles with pumice, the removal efficiency increased with increasing $\mathrm{pH}$ [24]. In a study conducted by Zhang et al. to remove chromium (VI) by diatomite with iron nanoparticles, the best removal efficiency occurred at $\mathrm{pH}=2-5$ and $\mathrm{pH}=3$ was selected as the optimum [40].

3.3. Absorbent Effect. The effect of the adsorbent on the removal efficiency of two processes D-nZVI and P-nZVI in 4 concentrations is shown in Figure 7. As shown in D-nZVI, the removal efficiency increases with increasing concentration first and then decreases, in fact, the optimal adsorbent concentration for D-nZVI was $1.42 \mathrm{~g} \cdot \mathrm{L}^{-1}$. However, in $\mathrm{P}-\mathrm{nZVI}$, the removal rate increased with increasing 


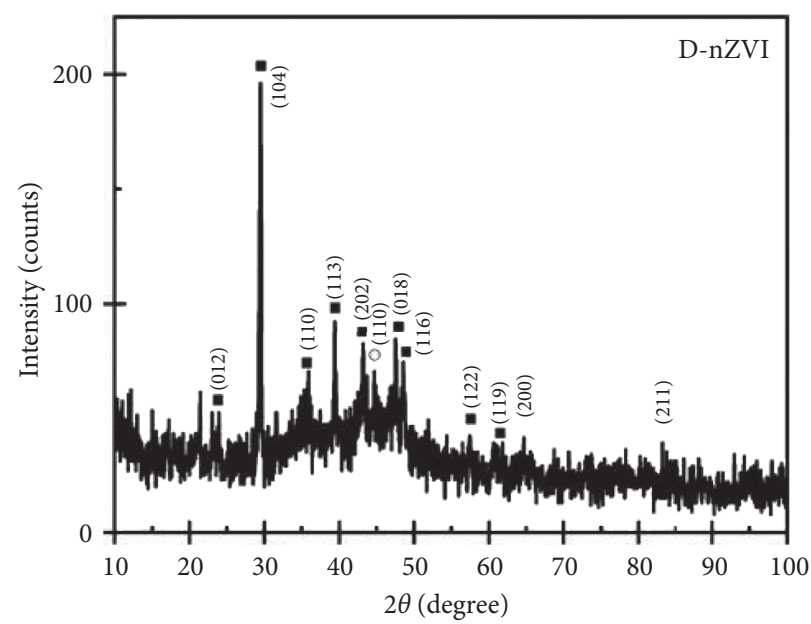

- $\mathrm{CaCO}_{3}$

- $\mathrm{Fe}^{0}$

(a)

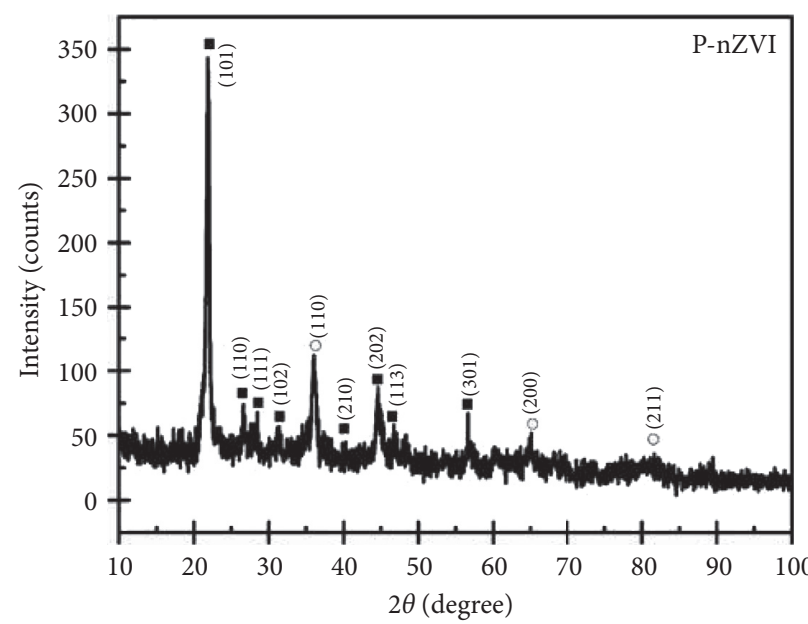

- $\mathrm{SiO}_{2}$

- $\mathrm{Fe}^{0}$

FIgURe 5: XRD spectrums of (a) D-nZVI and (b) P-nZVI.

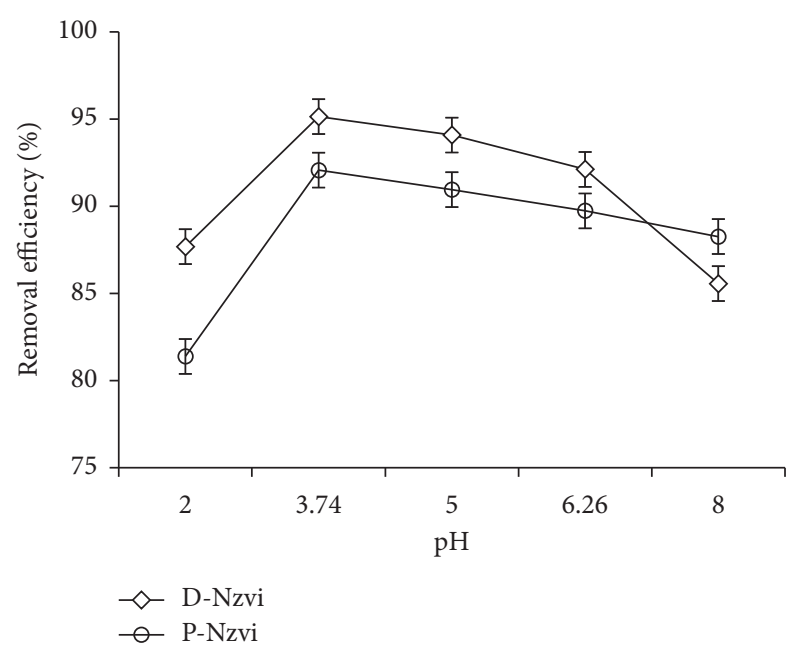

FIGURE 6: Effect of $\mathrm{pH}$ on paraquat removal by adsorption onto DnZVI and P-NZVI (paraquat herbicide: $0.5 \mathrm{mg} \cdot \mathrm{L}^{-1}$, time: $100 \mathrm{~min}$, adsorbent dose: $1.42 \mathrm{~g} \cdot \mathrm{L}^{-1}$ for D-nZVI, and $2 \mathrm{~g} \cdot \mathrm{L}^{-1}$ for P-nZVI).

adsorbent concentration, so that at a concentration of $2 \mathrm{~g} \cdot \mathrm{L}^{-1}$, it reached $95.75 \%$ efficiency.

The amount of adsorbent is another important factor in the removal process. Based on our results, the removal rate for P-nZVI adsorbent concentration was $95.75 \%$ at a concentration of $2 \mathrm{~g} \cdot \mathrm{L}^{-1}$ and for D-nZVI, $96.25 \%$ at a concentration of $1.42 \mathrm{~g} \cdot \mathrm{L}^{-1}$. The results suggest that possible mechanisms for the removal of paraquat from aqueous solutions include the uptake of paraquat by P-nZVI and the reduction of paraquat through the oxidation of $\mathrm{Fe}^{0}$ to $\mathrm{Fe}^{3}$. As well as, the results show that the higher amount of adsorbent and consequently the higher specific surface area lead to the higher removal efficiency. However, for D-nZVI, due to the higher number of available and active sites of the adsorbents, the removal efficiency was higher at first, and then it

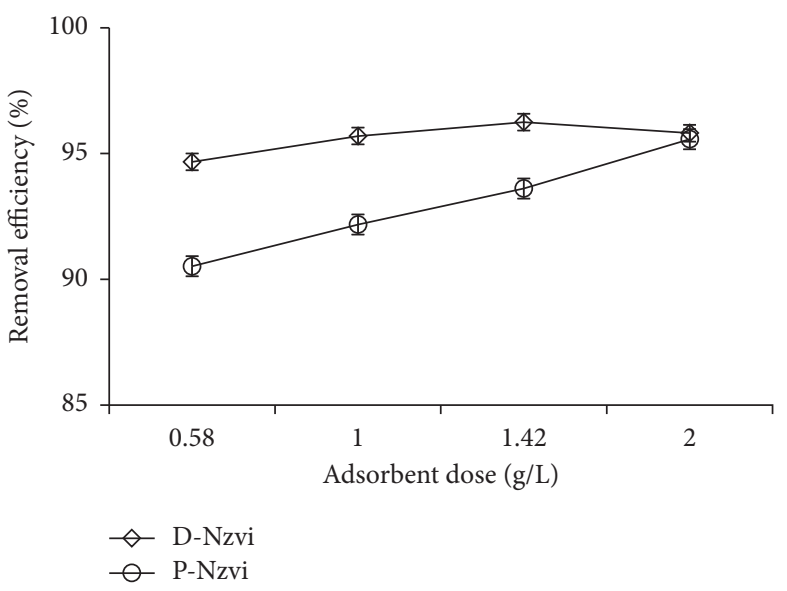

FIgURE 7: The effect of the adsorbent dose on the paraquat removal by adsorption onto D-nZVI and P-nZVI (paraquat herbicide: $0.5 \mathrm{mg} \cdot \mathrm{L}^{-1}$, time: $100 \mathrm{~min}$, and $\mathrm{pH}: 3$ ).

gradually decreased. It may be related to the occupation of the pores with adsorbate molecules [41]. The presented results are consistent with the results of the Gluer study to remove tetracycline by zero-valent iron nanoparticles with pumice [26]. Also, a similar study carried out by Harman and Genisoglu in 2016 on copper removal by P-nZVI yielded similar results [41]. In a study conducted by Dehestaniathar et al. on the uptake of fluoride by iron oxide nanoparticles stabilized on diatomite, the uptake increased with increasing adsorption [42].

3.4. Effect of Initial Paraquat Concentration. The effect of initial paraquat concentration on the removal efficiency of the two processes is shown in Figure 8. As observed, the highest removal efficiencies (93.27\% for P-nZVI and $96.94 \%$ for D-nZVI) are related to the concentration of $0.58 \mathrm{mg} \cdot \mathrm{L}^{-1}$ 


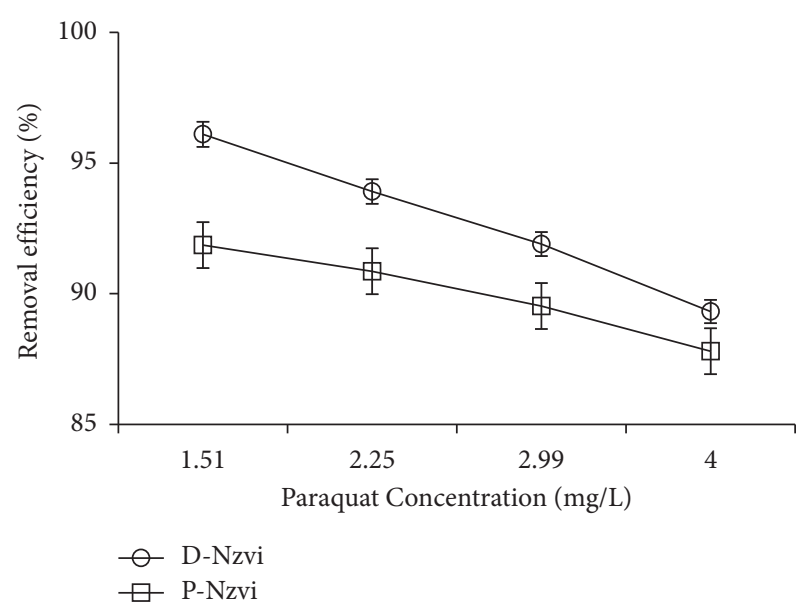

FIGURE 8: Effect of initial paraquat concentration on the paraquat removal by adsorption onto D-nZVI and P-nZVI ( $\mathrm{pH}$ : 3, time: $100 \mathrm{~min}$, and adsorbent dose: $1.42 \mathrm{~g} \cdot \mathrm{L}^{-1}$ for D-nZVI, $2 \mathrm{~g} \cdot \mathrm{L}^{-1}$ for P-nZVI).

paraquat. In both processes, the removal rate decreased as the initial paraquat concentration increased.

Increasing the paraquat concentration slightly reduces the adsorption efficiency because with increasing the toxin concentration, the amount of paraquat molecules in aqueous media increases and the interference of the intermediate compounds resulting from the initial decomposition increases as a result of competition between molecules over the adsorbent. Find and decrease removal efficiency, in most studies, the initial concentration of the contaminant is constant. In a study conducted by Shokoohi et al. to investigate the removal of phenol by pumice-coated iron from aqueous solutions, the efficiency first increased and then decreased with increasing contaminant concentration due to a decrease in adsorption capacity by the adsorbent [43]. Also, in another study conducted by Dehestaniathar et al. to adsorb fluoride by iron oxide nanoparticles stabilized on diatomite, the removal efficiency decreased with increasing fluoride concentration [42].

3.5. Time Effect. Figure 9 shows the effect of the contact time on the paraquat removal. In the P-nZVI process at the optimal contact time of $100 \mathrm{~min}$, the removal efficiency was $95.27 \%$. But in the D-nZVI process, after $74 \mathrm{~min}$, the removal efficiency is almost constant.

One of the influential factors in the elimination process is reaction time. According to the results, the highest removal percentage $(95.25 \%)$ was observed for P-nZVI at $100 \mathrm{~min}$. The reason can be attributed to the increase in the amount of $\mathrm{OH}$ radical produced as a result of increasing the contact time. Also, the highest removal percentage for D-nZVI was $95.91 \%$. In the D-nZVI process, diatomite prevents the accumulation of iron particles, resulting in increased efficiency, but after a while, due to the saturation of the adsorbent surface, the removal efficiency is almost constant [38,44].

The study by Dhaouadi and Adhoum investigated the removal of paraquat herbicide by an advanced oxidation

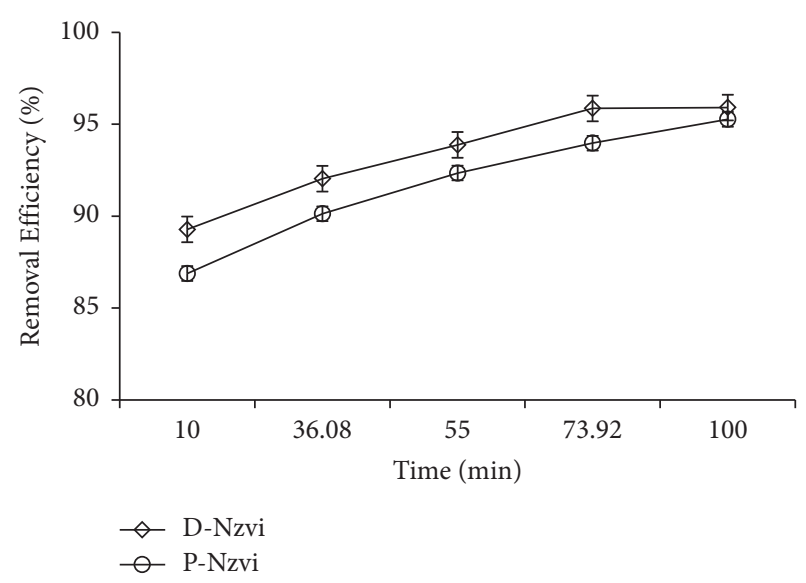

FIGURE 9: The effect of contact time on the paraquat removal by adsorption onto D-nZVI and P-nZVI (paraquat herbicide: $0.5 \mathrm{mg} \cdot \mathrm{L}^{-1}, \mathrm{pH}: 3$, and adsorbent dose: $1.42 \mathrm{~g} \cdot \mathrm{L}^{-1}$ for $\mathrm{D}-\mathrm{nZVI}$, $2 \mathrm{~g} \cdot \mathrm{L}^{-1}$ for P-nZVI).

process. Their findings showed that the removal efficiency was increased by increasing the contact time [45]. In the study of Babaeifar et al. on the removal of arsenic by pumicecoated iron, except for the first $20 \mathrm{~min}$, the removal efficiency remained constant [46]. In a study conducted by Liu et al. for the catalytic degradation of orange II from aqueous solutions using diatomite/nickel-reinforced iron-reinforced iron, the removal efficiency was increased first over time (by adding diatomite from the aggregation of $\mathrm{Fe} / \mathrm{Ni}$ nanoparticles) and then remained constant [24]. In the study conducted by Zha et al. to catalytically reduce methyl blue by combining diatomite with ZVI, the removal rate was increased by increasing the contact time [47].

3.6. Temperature Effect. In present study, the effect of paraquat removal efficiency was investigated for both the P-nZVI and D-nZVI processes. According to Figure 10, at $23.69^{\circ} \mathrm{C}$, the removal efficiencies were $91.96 \%$ and $95.02 \%$ for P-nZVI and D-nZVI, respectively.

According to the obtained results, the removal efficiency decreases with increasing temperature. There may be two possible explanations for this phenomenon: (1) paraquat mobility decreases with higher temperatures and (2) as the temperature increases, the activation energy of the decomposition reaction decreases [22, 47]. In a study conducted by Liu et al. to remove heavy metals by nanoparticles with pumice, the removal efficiency was increased with increasing temperature due to the structure of $\mathrm{Hg}$ [24]. In a study conducted by Zhang and Wang on the decomposition of methyl orange dye from aqueous solution using carbon nanoparticles with carbon, the efficiency was increased with temperature [48].

3.7. Adsorption Isotherms. In this study, two adsorption models of Langmuir and Freundlich were investigated. The results of the adsorption isotherms are listed in Figure 11 and the relative parameters calculated from the two models are listed in Table 1. For D-nZVI, the higher correlation 


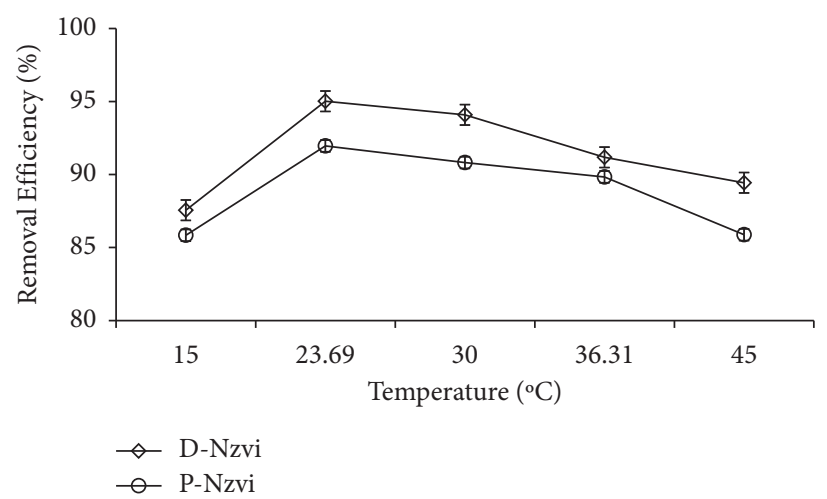

FIGURE 10: The effect of temperature on the paraquat removal by adsorption onto D-nZVI and P-nZVI (paraquat herbicide: 0.5 mg. $\mathrm{L}^{-1}$, time: $100 \mathrm{~min}, \mathrm{pH}$ : 3, and adsorbent dose: $1.42 \mathrm{~g} \cdot \mathrm{L}^{-1}$ for D-nZVI, $2 \mathrm{~g} \cdot \mathrm{L}^{-1}$ for P-nZVI).

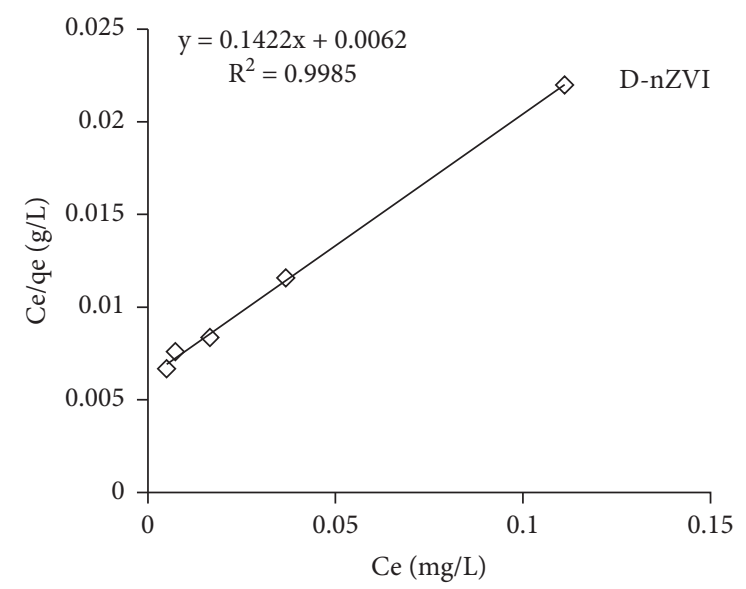

(a)

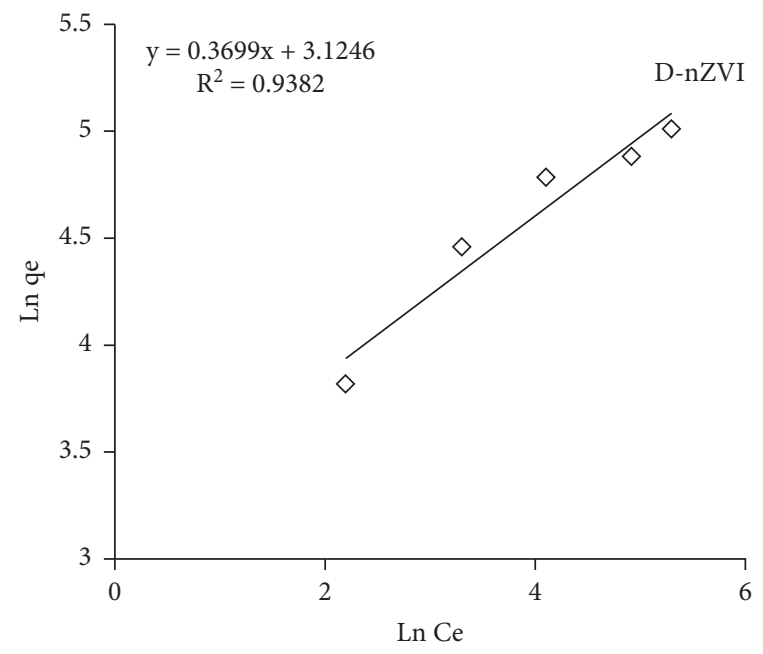

(c)

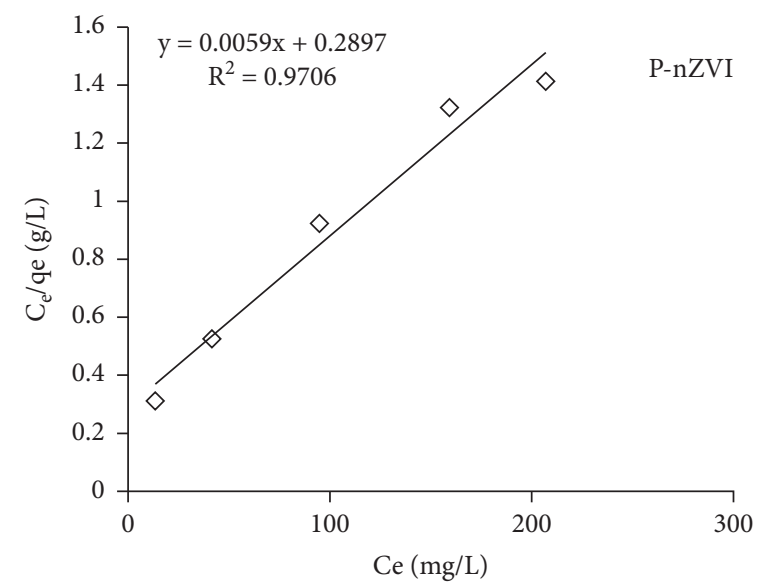

(b)

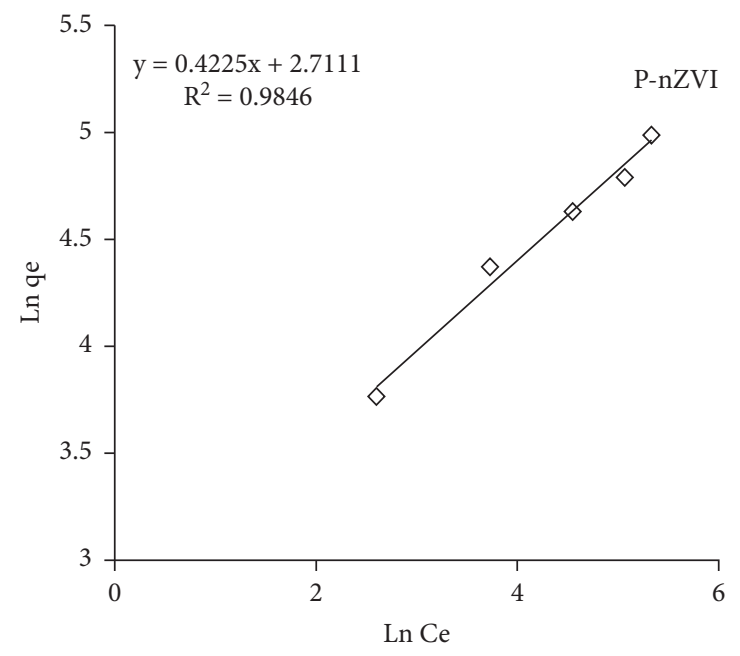

(d)

FIgURE 11: Paraquat adsorption isotherms on D-nZVI and P-nZVI adsorbents. (a, b) The Langmuir isotherm model and (c, d) the Freundlich isotherm model.

coefficient of the Langmuir model indicates that the adsorption data are better fitted by the Langmuir model $\left(R^{2}>0.99\right)$ than the Ferundlich model $\left(R^{2}>0.93\right)$. This means that the adsorption involved the formation of a monolayer on a homogeneous surface. For the P-nZVI adsorbent, as shown in Figure 11, experimental data excellently fits both the Langmuir and Freundlich isotherm models. Thus, the adsorption process occurred both on 
TABLE 1: Calculated parameters of the Langmuir-Freundlich model for D-nZVI and P-nZVI adsorbent.

\begin{tabular}{|c|c|c|c|c|c|c|c|c|}
\hline \multirow{3}{*}{$\begin{array}{l}\text { Model } \\
\text { Equation } \\
\text { Parameter }\end{array}$} & \multicolumn{4}{|c|}{ Langmuir } & \multicolumn{4}{|c|}{ Freundlich } \\
\hline & \multicolumn{4}{|c|}{$\left(C_{e} / q_{e}\right)=\left(1 / q_{m} k_{e}\right)+\left(C_{e} / q_{m}\right)$} & \multicolumn{4}{|c|}{$\operatorname{Ln} q_{e}=\operatorname{Ln} k_{f}+(1 / n) \operatorname{Ln} C_{e}$} \\
\hline & \multicolumn{2}{|c|}{$q_{\max }\left(\mathrm{mg} \cdot \mathrm{g}^{-1}\right)$} & \multicolumn{2}{|c|}{$K_{L}\left(\mathrm{~L} \cdot \mathrm{mg}^{-1}\right)$} & \multicolumn{2}{|c|}{$1 / n$} & \multicolumn{2}{|c|}{$K_{f}\left[\left(\mathrm{mg} \cdot \mathrm{g}^{-1}\right)\left(\mathrm{L} \cdot \mathrm{mg}^{-1}\right)^{1 / n}\right]$} \\
\hline Absorbent & D-nZVI & P-nZVI & D-nZVI & P-nZVI & D-nZVI & P-nZVI & D-nZVI & P-nZVI \\
\hline Amount & 161.3 & 169.4915 & 0.99 & 0.02 & 0.3699 & 0.4225 & 22.75 & 15.04 \\
\hline
\end{tabular}

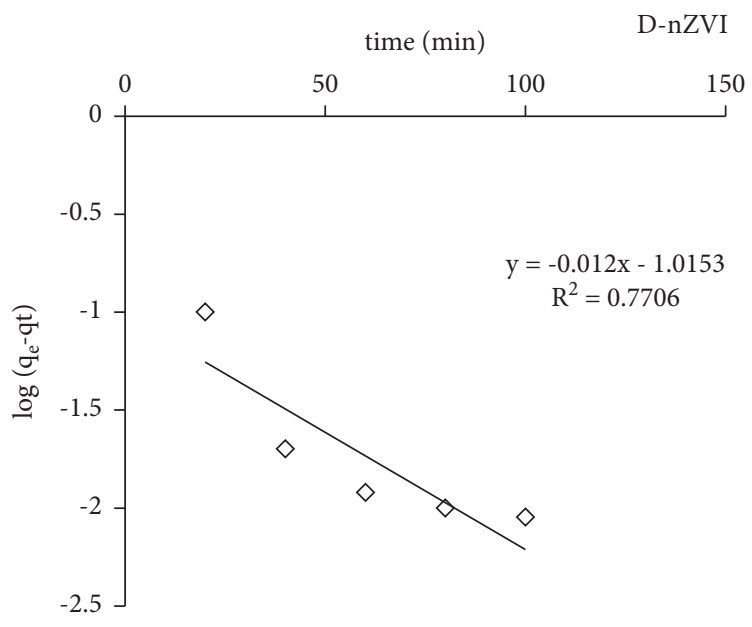

(a)

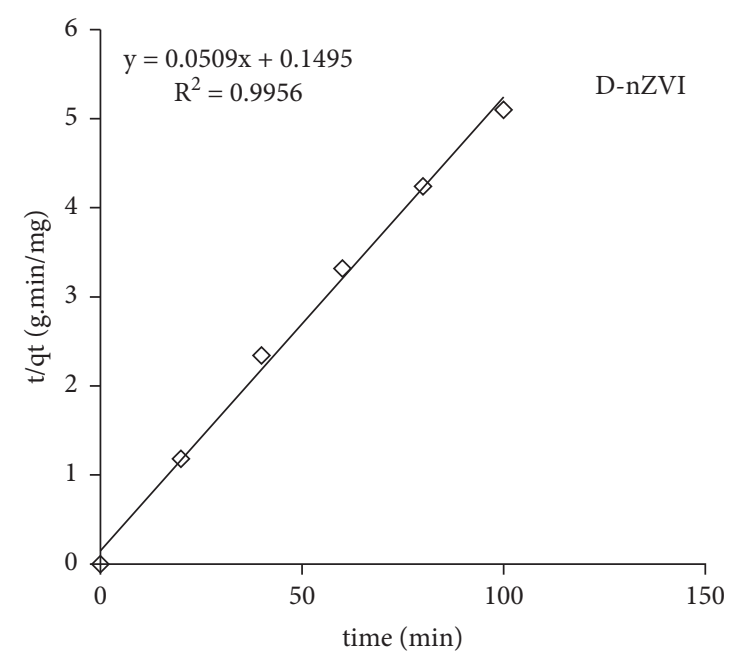

(c)

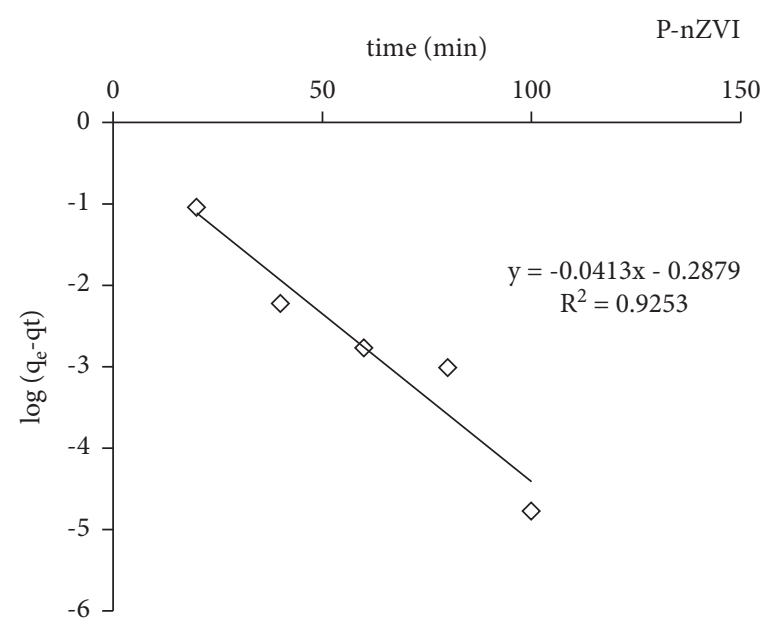

(b)

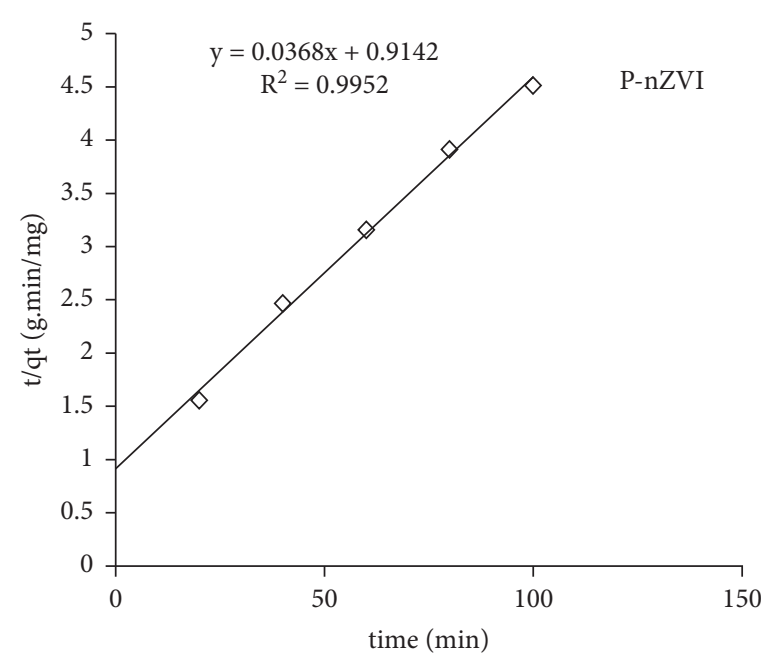

(d)

Figure 12: Adsorption kinetic study of D-nZVI and b P-nZVI. (a, b) The pseudo-first-order model and (c, d) the pseudo-second-order model.

homogeneous adsorbent surfaces and reversible heterogeneous surfaces in the adsorption sites. The maximum adsorption capacity $\left(q_{m}\right)$ of paraquat for D-nZVI and P-nZVI was $161.3 \mathrm{mg} \cdot \mathrm{g}^{-1}$ and $169.49 \mathrm{mg} \cdot \mathrm{g}^{-1}$, respectively. The results of D-nZVI are consistent with a study conducted by Froutan et al. [49]. The results of P-nZVI are also consistent with the results of a study conducted by Gular to remove tetracycline [26].
3.8. Adsorption Kinetics. To investigate kinetic studies, pseudo-first-order kinetics and pseudo-second-order kinetics were used. The results showed that both processes follow a pseudo-second-order model and show a correlation coefficient above 0.9 (Figure 12 and Table 2). These results showed that the velocity control phase in the adsorption process may be chemical and that paraquat adsorption probably occurs through Van der Waals forces or ion 
TABLE 2: Calculated parameters related to pseudo-second-order kinetics for D-nZVI and P-nZVI adsorbents.

\begin{tabular}{|c|c|c|c|c|c|c|c|c|}
\hline \multirow{3}{*}{$\begin{array}{l}\text { Model } \\
\text { Equation } \\
\text { Parameter }\end{array}$} & \multicolumn{4}{|c|}{ Pseudo-first-order kinetics } & \multicolumn{4}{|c|}{ Pseudo-second-order kinetics } \\
\hline & \multicolumn{4}{|c|}{$\log \left(q_{e}-q_{t}\right)=\log \left(q_{e}\right)-\left(k_{1} / 2.3\right) t$} & \multicolumn{4}{|c|}{$\left(t / q_{t}\right)=\left(1 / q_{e}^{2} k_{2}\right)+\left(t / q_{e}\right)$} \\
\hline & \multicolumn{2}{|c|}{$q_{e}\left(\mathrm{mg} \cdot \mathrm{g}^{-1}\right)$} & \multicolumn{2}{|c|}{$K_{1}\left(\min ^{-1}\right)$} & \multicolumn{2}{|c|}{$q_{e}\left(\mathrm{mg} \mathrm{g}^{-1}\right)$} & \multicolumn{2}{|c|}{$K_{2}\left(\mathrm{~g} \cdot \mathrm{mg}^{-1} \cdot \mathrm{min}^{-1}\right)$} \\
\hline Absorbent & D-nZVI & P-nZVI & D-nZVI & P-nZVI & D-nZVI & P-nZVI & D-nZVI & P-nZVI \\
\hline Amount & 1.0153 & 0.2879 & 0.012 & 0.0413 & 6.68 & 1.0938 & 0.0509 & 0.0368 \\
\hline
\end{tabular}

TABLE 3: Comparison of the adsorption capacities of paraquat herbicide with other adsorbents.

\begin{tabular}{lccc}
\hline Adsorbent & $q_{m}\left(\mathrm{mg}^{-1}\right)$ & Equilibrium time $(\mathrm{min})$ & References \\
\hline Carbon tubes from biomass & 218.61 & 20 & 60 \\
Activated clay & 58.48 & 2 & {$[50]$} \\
Bentonite/zero-valent iron & 6.78 & 140 & {$[51]$} \\
Activated date & 55.56 & 420 & {$[52]$} \\
Polyester textile coated with cyclodextrin polymer & 24.20 & 100 & Present \\
\hline D-nZVI & 161.3 & $54]$ & Study \\
P-nZVI & 169.49 & & \\
\hline
\end{tabular}

exchange between the adsorbent and paraquat. The results are consistent with the studies of Zhang and Wang [40].

3.9. Comparison of Adsorption Capacity of D-nZVI and $P-n Z V I$ Composites. The adsorption capacity of the D-nZVI and P-nZVI composites prepared in the present work was compared with those of various sorbents for removal of paraquat herbicide which are represented in Table 3. Generally, the comparison of the various adsorbents obtained with the others was not simple due to various experimental conditions. One of the important superiority of D-nZVI and P-nZVI composites compared with other sorbents was their high adsorption capacity, while some sorbents had a lower absorption capacity.

\section{Conclusion}

In the present study, the determination of the optimal values affecting the D-nZVI and P-nZVI processes in order to remove the paraquat herbicide was investigated, and the optimal process conditions were determined. Also, the properties of each adsorbent were determined according to SEM, FTIR, BET, and XDR analyses, which showed that diatomite and pumice were well fixed on iron nanoparticles and prevented their accumulation. The optimal values obtained in the P-nZVI process were $0.5 \mathrm{mg} \cdot \mathrm{L}^{-1}$ paraquat herbicide with $2 \mathrm{~g} \cdot \mathrm{L}^{-1}$ adsorbent and contact time was $100 \mathrm{~min}$, and the optimal values obtained in the D-nZVI process were $0.5 \mathrm{mg} \cdot \mathrm{L}^{-1}$ paraquat herbicide with $1.42 \mathrm{~g} \cdot \mathrm{L}^{-1}$ adsorbent at a contact time of $100 \mathrm{~min}$. The optimum $\mathrm{pH}$ in both processes was 3.74. Based on our results, it was found that under optimal conditions, P-nZVI and D-nZVI processes, paraquat herbicide can be removed $85.28 \%$ and $92.76 \%$, respectively. The contact time was effective in the removal efficiency in both processes, so that as the contact time increased, the removal efficiency also increased. The maximum adsorption capacities for D-nZVI and P-nZVI are $161.3 \mathrm{mg} \cdot \mathrm{g}^{-1}$ and $169.49 \mathrm{mg} \cdot \mathrm{g}^{-1}$, respectively. The mechanism of the adsorption process in D-nZVI follows the Langmuir isotherm $\left(R^{2}=0.99\right)$ and in P-nZVI follows two models of Langmuir $\left(R^{2}=0.97\right)$ and the Freundlich isotherm $\left(R^{2}=0.98\right)$. Adsorption kinetics in both processes are pseudo-second-order models. It can be concluded that the D-nZVI process is more effective for paraquat removal due to its higher removal efficiency. These processes can be used to remove contaminants with similar structures due to their low cost, high adsorption capacity, easy operation, and workability in environmental conditions.

\section{Data Availability}

The data used to support the findings of this article are included within the article.

\section{Conflicts of Interest}

The authors declare that they have no conflicts of interest.

\section{Acknowledgments}

The authors thank the Shahrekord University of Medical Sciences (grant number: 3243) for supporting this study. The authors of this paper appreciate the authorities of Shahrekord University of Medical Sciences, who have fully involved in this research.

\section{Supplementary Materials}

Table S1: characteristics of paraquat. Table S2: statistical parameters obtained from measuring size of 100 particles in the studied samples. (Supplementary Materials)

\section{References}

[1] T. O. Ikpesu, "Assessment of occurrence and concentrations of paraquat dichloride in water, sediments and fish from warri river Basin, Niger Delta, Nigeria," Environmental Science and Pollution Research, vol. 22, no. 11, pp. 8517-8525, 2015. 
[2] D. Kumari and S. John, "Safety and occupational health hazards of agricultural workers handling pesticides: a case study," in Advances in Health and Environment Safety, pp. 75-82, Springer, Berlin, Germany, 2018.

[3] C. P. Nanseu-Njiki, G. K. Dedzo, and E. Ngameni, "Study of the removal of paraquat from aqueous solution by biosorption onto ayous (triplochiton schleroxylon) sawdust," Journal of Hazardous Materials, vol. 179, no. 1-3, pp. 63-71, 2010.

[4] R. J. Smeyne, C. B. Breckenridge, M. Beck et al., "Assessment of the effects of MPTP and paraquat on dopaminergic neurons and microglia in the substantia nigra pars compacta of C57BL/6 mice," PLoS One, vol. 11, no. 10, Article ID e0164094, 2016.

[5] X.-F. Zhang, M. Thompson, and Y.-H. Xu, "Multifactorial theory applied to the neurotoxicity of paraquat and paraquatinduced mechanisms of developing Parkinson's disease," Laboratory Investigation, vol. 96, no. 5, Article ID 496, 2016.

[6] I. K. Cho, M. Jeong, A.-S. You, K. Hun Park, and Q. X Li, "Pulmonary proteome and protein networks in response to the herbicide paraquat in rats," Journal of Proteomics \& Bioinformatics, vol. 8, no. 5, Article ID 67, 2015.

[7] M. Zbair, Z. Anfar, H. Ait Ahsaine, and H. Khallok, "Kinetics, equilibrium, statistical surface modeling and cost analysis of paraquat removal from aqueous solution using carbonated jujube seed," RSC Advances, vol. 9, no. 2, pp. 1084-1094, 2019.

[8] S. Jafarinejad, "Recent advances in determination of herbicide paraquat in environmental waters and its removal from aqueous solutions: a review," International Research Journal of Applied and Basic Sciencesi, vol. 9, pp. 1758-1774, 2015.

[9] M. D. Pavlović, A. Buntić, S. Šiler-Marinković et al., "Spent coffee grounds as adsorbents for pesticide paraquat removal from its aqueous solutions," in Proceedings of the International Conference on Civil, Biological and Environmental Engineering (CBEE-2014), Kuala Lumpur, Malaysia, April 2014.

[10] C. Oliveira, K. Gruskevica, T. Juhna, K. Tihomirova, A. Alves, and L. M. Madeira, "Removal of paraquat pesticide with Fenton reaction in a pilot scale water system," Drinking Water Engineering and Science, vol. 7, no. 1, pp. 11-21, 2014.

[11] M. S. F. Santos, A. Alves, and L. M. Madeira, "Paraquat removal from water by oxidation with Fenton's reagent," Chemical Engineering Journal, vol. 175, pp. 279-290, 2011.

[12] U. C. Ugochukwu, A. Ochonogor, C. M. Jidere et al., "Exposure risks to polycyclic aromatic hydrocarbons by humans and livestock (cattle) due to hydrocarbon spill from petroleum products in Niger-delta wetland," Environment International, vol. 115, pp. 38-47, 2018.

[13] H. Dong, C. Zhang, K. Hou et al., "Removal of trichloroethylene by biochar supported nanoscale zero-valent iron in aqueous solution," Separation and Purification Technology, vol. 188, pp. 188-196, 2017.

[14] R. A. Crane and T. B. Scott, "Nanoscale zero-valent iron: future prospects for an emerging water treatment technology," Journal of Hazardous Materials, vol. 211-212, pp. 112-125, 2012.

[15] S. Luo, P. Qin, J. Shao, L. Peng, Q. Zeng, and J.-D. Gu, "Synthesis of reactive nanoscale zero valent iron using rectorite supports and its application for orange II removal," Chemical Engineering Journal, vol. 223, pp. 1-7, 2013.

[16] X. Jiang, Z. Ouyang, Z. Zhang et al., "Mechanism of glyphosate removal by biochar supported nano-zero-valent iron in aqueous solutions," Colloids and Surfaces A: Physicochemical and Engineering Aspects, vol. 547, pp. 64-72, 2018.

[17] X. Lv, J. Xu, G. Jiang, and X. Xu, "Removal of chromium(VI) from wastewater by nanoscale zero-valent iron particles supported on multiwalled carbon nanotubes," Chemosphere, vol. 85, no. 7, pp. 1204-1209, 2011.

[18] A. Khodabakhshi, M. M. Amin, and M. Mozaffari, "Synthesis of magnetite nanoparticles and evaluation of its efficiency for arsenic removal from simulated industrial wastewater," Iranian Journal of Environmental Health Science \& Engineering, vol. 8, no. 3, pp. 189-200, 2011.

[19] G. Sheng, X. Shao, Y. Li et al., "Enhanced removal of uranium(VI) by nanoscale zerovalent iron supported on $\mathrm{Na}-$ bentonite and an investigation of mechanism," The Journal of Physical Chemistry A, vol. 118, no. 16, pp. 2952-2958, 2014.

[20] I. Dror, O. M. Jacov, A. Cortis, and B. Berkowitz, "Catalytic transformation of persistent contaminants using a new composite material based on nanosized zero-valent iron," ACS Applied Materials \& Interfaces, vol. 4, no. 7, pp. 3416-3423, 2012.

[21] Z. Sun, Y. Zhang, S. Zheng, Y. Park, and R. L. Frost, "Preparation and thermal energy storage properties of paraffin/calcined diatomite composites as form-stable phase change materials," Thermochimica Acta, vol. 558, pp. 16-21, 2013.

[22] J. Shen, C. Ou, Z. Zhou et al., "Pretreatment of 2,4-dinitroanisole (DNAN) producing wastewater using a combined zero-valent iron (ZVI) reduction and Fenton oxidation process," Journal of Hazardous Materials, vol. 260, pp. 993-1000, 2013.

[23] P. Yuan, D. Liu, M. Fan et al., "Removal of hexavalent chromium [Cr (VI)] from aqueous solutions by the diatomitesupported/unsupported magnetite nanoparticles," Journal of Hazardous Materials, vol. 173, no. 1-3, pp. 614-621, 2010.

[24] T. Liu, Z.-L. Wang, and Y. Sun, "Manipulating the morphology of nanoscale zero-valent iron on pumice for removal of heavy metals from wastewater," Chemical Engineering Journal, vol. 263, pp. 55-61, 2015.

[25] Z. Sun, S. Zheng, G. A. Ayoko, R. L. Frost, and Y. Xi, "Degradation of simazine from aqueous solutions by diatomite-supported nanosized zero-valent iron composite materials," Journal of Hazardous Materials, vol. 263, pp. 768-777, 2013.

[26] U. A. Guler, "Removal of tetracycline from aqueous solutions using nanoscale zero valent iron and functional pumice modified nanoscale zero valent iron," Journal of Environmental Engineering and Landscape Management, vol. 25, no. 3, pp. 223-233, 2017.

[27] F. Mohammadi-Moghadam, M. Mehdi Amin, M. Khiadani, F. Momenbeik, H. Nourmoradi, and M. Sadegh Hatamipour, "Application of Glycyrrhiza glabra root as a novel adsorbent in the removal of toluene vapors: equilibrium, kinetic, and thermodynamic study," Journal of Environmental and Public Health, vol. 2013, Article ID 986083, 7 pages, 2013.

[28] F. Mohammadi-Moghadam, A. Khodabakhshi, M. Farhadkhani et al., "Removal of trichloroethylene by clay modified with cationic surfactant in aqueous solutions: equilibrium, kinetic, and thermodynamic study," Journal of Surfactants and Detergents, vol. 23, no. 6, pp. 1099-1109, 2020.

[29] H. Hossini and P. Makhdoumi, "Optimization of the electrocoagulation process for sulfate removal using response surface methodology," Bulgarian Chemical Communications, vol. 47 , pp. 63-71, 2015.

[30] A. Shafiu Kamba, M. Ismail, T. A. Tengku Ibrahim, and Z. A. Bakar Zakaria, "Synthesis and characterisation of calcium carbonate aragonite nanocrystals from cockle shell powder (Anadara granosa)," Journal of Nanomaterials, vol. 2013, Article ID 398357, 9 pages, 2013. 
[31] M. Galván-Ruiz, J. Hernández, L. Baños, J. Noriega-Montes, and M. E. Rodríguez-García, "Characterization of calcium carbonate, calcium oxide, and calcium hydroxide as starting point to the improvement of lime for their use in construction," Journal of Materials in Civil Engineering, vol. 21, no. 11, pp. 694-698, 2009.

[32] B. Cheng, W. Cai, and J. Yu, "DNA-mediated morphosynthesis of calcium carbonate particles," Journal of Colloid and Interface Science, vol. 352, no. 1, pp. 43-49, 2010.

[33] M. R. Jung, F. D. Horgen, S. V. Orski et al., "Validation of ATR FT-IR to identify polymers of plastic marine debris, including those ingested by marine organisms," Marine Pollution Bulletin, vol. 127, pp. 704-716, 2018.

[34] A. Shahmoradi, M. Ranjbarghanei, A. A. Javidparvar, L. Guo, E. Berdimurodov, and B. Ramezanzadeh, "Theoretical and surface/electrochemical investigations of walnut fruit green husk extract as effective inhibitor for mild-steel corrosion in $1 \mathrm{M} \mathrm{HCl}$ electrolyte," Journal of Molecular Liquids, vol. 338, Article ID 116550, 2021.

[35] X. Tai, J. H. Ma, Z. Du, W. Wang, and J. Wu, “A simple method for synthesis of thermal responsive silica nanoparticle/PNIPAAm hybrids," Powder Technology, vol. 233, pp. 47-51, 2013.

[36] M. Liu, L. Gan, L. Chen et al., "A novel liposome-encapsulated hemoglobin/silica nanoparticle as an oxygen carrier," International Journal of Pharmaceutics, vol. 427, no. 2, pp. 354-357, 2012.

[37] S. R. Purohit, L. E. Jayachandran, A. S. Raj, D. Nayak, and P. S. Rao, "X-ray diffraction for food quality evaluation," in Evaluation Technologies for Food Quality, pp. 579-594, Elsevier, Amsterdam, Netherlands, 2019.

[38] Y. Zhang, Y. Li, and X. Zheng, "Removal of atrazine by nanoscale zero valent iron supported on organobentonite," The Science of the Total Environment, vol. 409, no. 3, pp. 625-630, 2011.

[39] T. Dombek, D. Davis, J. Stine, and D. Klarup, “Degradation of terbutylazine (2-chloro-4-ethylamino-6-terbutylamino1,3,5-triazine), deisopropyl atrazine (2-amino-4-chloro-6ethylamino-1,3,5-triazine), and chlorinated dimethoxy triazine (2-chloro-4,6-dimethoxy-1,3,5-triazine) by zero valent iron and electrochemical reduction," Environmental Pollution, vol. 129, no. 2, pp. 267-275, 2004.

[40] Y. Zhang, Z. Tian, Q. Jing, Y. Chen, and X. Huang, "Removal of $\mathrm{Cr}(\mathrm{VI})$ by modified diatomite supported NZVI from aqueous solution: evaluating the effects of removal factors by RSM and understanding the effects of $\mathrm{pH}$," Water Science and Technology, vol. 80, no. 2, pp. 308-316, 2019.

[41] B. I. Harman and M. Genisoglu, "Synthesis and characterization of pumice-supported nZVI for removal of copper from waters," Advances in Materials Science and Engineering, vol. 2016, Article ID 4372136, 10 pages, 2016.

[42] S. Dehestaniathar, S. H. Amini, A. Maleki, B. Shahmoradi, N. Reshadmanesh, and P. Teymouri, "Adsorption of fluoride using diatomite-supported ferric oxide nanoparticles: determination of optimum condition, kinetics, and adsorption isotherms," Iranian Journal of Health and Environment, vol. 9, no. 2, pp. 185-196, 2016.

[43] R. Shokoohi, Z. Torkshavand, S. Bajalan, H. Zolghadnasab, and Z. Khodayari, "Efficient phenol removal from aqueous solution using iron-coated pumice and leca as an available adsorbents: evalution of kinetics and isotherm studies," Global Nest Journal, vol. 21, no. 2, pp. 91-97, 2019.

[44] J. Shao, X. Yu, M. Zhou, X. Cai, and C. Yu, "Nanoscale zerovalent iron decorated on bentonite/graphene oxide for removal of copper ions from aqueous solution," Materials, vol. 11, no. 6, Article ID 945, 2018.

[45] A. Dhaouadi and N. Adhoum, "Degradation of paraquat herbicide by electrochemical advanced oxidation methods," Journal of Electroanalytical Chemistry, vol. 637, no. 1-2, pp. 33-42, 2009.

[46] L. B. L. Babaiefar, B. Souri, M. Heidari, and R. Khoshnavazi, "Evaluation of iron and manganese-coated pumice application for the removal of as (v) from aqueous solutions," Iranian Journal of Environmental Health Science \& Engineering, vol. 9, no. 1, pp. 21-29, 2012.

[47] Y. Zha, Z. Zhou, H. He, T. Wang, and L. Luo, "Nanoscale zero-valent iron incorporated with nanomagnetic diatomite for catalytic degradation of methylene blue in heterogeneous Fenton system," Water Science and Technology, vol. 73, no. 11, pp. 2815-2823, 2016.

[48] B. Zhang and D. Wang, "Preparation of biomass activated carbon supported nanoscale zero-valent iron (Nzvi) and its application in decolorization of methyl Orange from aqueous solution," Water, vol. 11, no. 8, Article ID 1671, 2019.

[49] A. Foroutan, A. Khodadadi Darbaan, R. Sarraf Mamouri, Y. Kiani Nia, and B. Rahnamaye Moghadam, "Investigation of surface adsorption properties of nickel metal using three nZVI, nZVI-D and mineral diatom absorbers," Iranian Journal of Chemistry and Chemical Engineering (International English Edition), vol. 34, no. 3, pp. 1-11, 2015.

[50] H. Li, H. Qi, M. Yin, Y. Chen, Q. Deng, and S. Wang, "Carbon tubes from biomass with prominent adsorption performance for paraquat," Chemosphere, vol. 262, Article ID 127797, 2021.

[51] W. T. Tsai, C. W. Lai, and K. J. Hsien, "Effect of particle size of activated clay on the adsorption of paraquat from aqueous solution," Journal of Colloid and Interface Science, vol. 263, no. 1, pp. 29-34, 2003.

[52] Z. Dehgani, M. Sedghi asl, M. Ghaedi, M. M. Sabzehmeidani, and E. Adhami, "Removal of paraquat from aqueous solutions by a bentonite modified zero-valent iron adsorbent," New Journal of Chemistry, vol. 44, no. 31, pp. 13368-13376, 2020.

[53] M. Danish, O. Sulaiman, M. Rafatullah, R. Hashim, and A. Ahmad, "Kinetics for the removal of paraquat dichloride from aqueous solution by activated date (phoenix dactylifera) stone carbon," Journal of Dispersion Science and Technology, vol. 31, no. 2, pp. 248-259, 2010.

[54] J. Junthip, N. Jumrernsuk, P. Klongklaw, W. Promma, and S. Sonsupap, "Removal of paraquat herbicide from water by textile coated with anionic cyclodextrin polymer," SN Applied Sciences, vol. 1, no. 1, pp. 1-12, 2019. 